\title{
In silico analysis for the repurposing of broad-spectrum antiviral drugs against multiple targets from SARS-CoV-2: A molecular docking and ADMET approach
}

Arpana Parihar ( $\square$ arpana_parihar@yahoo.com )

Advanced Materials and Processes Research Institute CSIR https://orcid.org/0000-0003-3678-9405

Tabassum Zafar

Barkatullah Vishwavidyalaya: Barkatullah University

Rekha Khandia

Barkatullah Vishwavidyalaya: Barkatullah University

Dipesh Singh Parihar

Barkatullah Vishwavidyalaya: Barkatullah University

Rupali Dhote

Barkatullah Vishwavidyalaya: Barkatullah University

Yogesh Mishra

Barkatullah Vishwavidyalaya: Barkatullah University

\section{Research Article}

Keywords: SARS-CoV-2, COVID-19, Drug Purposing, Zanamivir, Herbacetin, Adefovir, Ribavirin, molecular docking

Posted Date: February 11th, 2022

DOI: https://doi.org/10.21203/rs.3.rs-1242644/v1

License: (c) (1) This work is licensed under a Creative Commons Attribution 4.0 International License. Read Full License 


\section{Abstract}

Background: Amidst the second wave of COVID-19 pandemic caused by severe acute respiratory syndrome coronavirus-2 (SARS-CoV-2) led the world devastated, and resulted in the death of millions of people with its deadly virulence potential. In comparison to similar virus outbreaks, such as severe acute respiratory syndrome coronavirus (SARS CoV) and middle east respiratory syndrome coronavirus (MERS CoV), COVID-19 led to severe morbidity and mortality. Various therapeutic interventions to combat the SARS-CoV-2 infection are actively investigated, but still, there is no specific drug with high anti-viral efficacy against the SARS-CoV-2 virus has been reported yet. The present work is an effort to represent the promising therapeutic efficacy of 52 broad-spectrum antiviral drugs as a potential lead molecule to suppress SARS-CoV-2 infection. These are the drugs that have shown potential efficacy against several viral infections earlier. The present article discusses the comparative analysis of the therapeutic efficacy of available broad-spectrum anti-viral drugs via assessment of receptor-ligand interaction using the molecular docking approach.

Results: Based on the molecular docking indications, we predict the potential importance of various broad-spectrum antiviral drugs that can be repurposed for the treatment of SARS-CoV-2. Molecular docking revealed that Remedesivir, Imatinib, Herbacetin, Zanamivir, Ribavirin, Dasabuvir, Rhoifolin, Sofosbuvir, Cirsimaritin, and $2 \mathrm{H}$-Cyclohepta[b]thiophene-3-carboxamide having strong interactions with respective targets.

Conclusion: The present piece of work strongly recommends the anti-viral potential of Zanamivir for RdRp enzyme inhibition, Herbacetin against receptor binding domain of spike protein, and main protease target, Adefovir for ACE2, and Ribavirin for endoribonuclease active site. The current predictions will enhance the clinical development of potential therapeutic drugs to combat the pandemic significantly.

\section{Background}

The emergence of severe acute respiratory syndrome 2 (SARS-CoV-2) creates a critical health emergency that has devastated the health care system along with the loss of millions of lives. The pendemic spreads almost all countries of the world and people are living under the threat of the highly contagious infectious disease COVID-19. At the time when the manuscript was written, the estimated R naught (R0) value of SARS-CoV-2 is estimated to be 2.5 (range $1 \cdot 8-3 \cdot 6)$, which was higher in comparison to SARS CoV, which had $R$ naught value ranges from $2 \cdot 0$ to $3 \cdot 0$. A high R0 value indicates the high virulence potential of SARS-CoV-2. The person-to-person transmission is consistently spreading, while the researchers are busy making large-scale efforts to combat the situation [1-4].

SARS-CoV-2 belongs to the genus Beta of the Coronaviridae family of enveloped single-stranded, positive-sense ribonucleic acid (RNA) with a genome length of 30,000bp. The virion is composed of various non-structural (RNA dependent RNA polymerase also known as RdRp) and structural proteins such as Spike (S), Nucleocapsid (N), Matrix (M), and Envelope (E) proteins. RdRp is a vital enzyme in the life cycle of RNA viruses, including coronaviruses. The genome has 14 Open Reading Frames (ORFs), which code information about 27 structural and non-structural proteins. This SARS family contains 14 binding residues, of which 8 amino acids are explicitly preserved for SARS-CoV-2. The most important thing is that the binding residues of this family interact with the ACE2 receptors present in the body directly $[1,4]$.

The extreme Acute Respiratory Distress Syndrome (ARDS) caused by the novel coronavirus results in severe inflammation of lungs wherein fluid builds up around and within the lungs resulting in pneumonia and septic shock due to a dramatic decrease in blood pressure followed by reduced oxygen saturation of body organs. Previously known similar infectious agents include Middle East Respiratory Syndrome MERS-CoV and SARS CoV [5-8], infect the lower respiratory system, by wreaking damage to the pulmonary epithelial cells and deliver their nucleocapsid material inside the cells which than replicate in the cytoplasm by taking over the control of cellular machinery. Besides, other organs, including the heart, kidney, liver, gastrointestinal system, and central nervous system, also get affected [6].

The continuing negative effect of the SARS-CoV-2 outbreak potentially poses significant challenges to the global health systems and has far-reaching effects for the global economy and survival efficacy, if the spread of the virus is not effectively managed. The process of research and development of a new molecule is a costly and labor-intensive process. Besides, SARS-CoV-2 is far more contagious compared to other fluviruses as one pre-symptomatic or asymptomatic person is capable to infect $>2$ healthy individuals.

In the existing scenario, efforts for drug repurposing of every existing anti-viral molecule could potentially lead further that possibly help the health care system with low labor and reduced cost. Many broad-spectrum anti-viral drugs could further serve mankind as a therapeutically potent molecule [3].

Lopinavir, Remdesivir, Hydroxychloroquine, Chloroquine, Azithromycin, Ascorbic Acid, Oseltamivir, Favipiravir, Umifenovir are some of the popular drugs that are potentially explored for their anti-viral efficacy by researchers from various regions including the USA, Russia, Brazil, Spain, Germany, Turkey, South Korea, Italy, and China against SARS-CoV-2 infection [9].

Currently, the most approved anti-viral compounds are virus replication inhibitors. Viral polymerases are one of the prominent drug targets in both types of non-nucleoside allosteric inhibitors and nucleoside analogs [10]. In these testing times, target-based drug predictions have helped clinicians to find out the most promising drug molecules $[2,11]$. Apart from replication inhibitors, SARS-CoV-2 main protease inhibitors such as nelfinavir, lopinavir, ritonavir, and aketoamide type protease drugs have also shown potential efficacy as anti-SARS-CoV-2 therapy [12, 13].

Nucleoside analogs and HIV-protease inhibitors are looked upon as promising treatment methods, besides RNA-dependent RNA polymerase (RdRp) and ACE2. Anti-viral drugs like Favinapir, Ritonavir, Oseltamivir, Lopinavir, Ganciclovir, and Remdesivir are clinically tested against COVID-19 infection. While the most popular drugs such as Lopinavir or Ritonavir that have the anti-viral potency against SARS-CoV-2, also face many issues to serve the population in this restricted time frame of emergency. The role of Remdesivir is extensively elucidated by various clinical outcomes (Recommendations for treatment of critically ill Covid-19 patients Version 3 S1 guidelines). Herbacetin, Rhoifolin, and Pectolinarin were found to efficiently block the enzymatic activity of SARS-CoV-2. Two 
clinical studies reveal the comfort in the patients of SARS-CoV-2 induced pneumonia and respiratory discomfort by use of a combination of drugs such as Lopinavir, Ritonavir. Many trials have shown the anti-viral potential of lopinavir-ritonavir against COVID-19. Darunavir, Favipiravir, Umifenovir, Arbidol, Carrimycin, Xiyanping, Danoprevir have also been clinically tested to observe the absolute and co-adjuvant therapeutic efficacy against the SARS-CoV-2 virus [14-17]. Further, some phototherapeutic formulations due to their high polyphenol content showed enhanced treatment efficacy. The United States Food and Drug Administration (FDA) has recommended Darunavir, another HIV protease inhibitor for the treatment of COVID-19. However, immunosuppression of lung inflammation and lung injury caused by anti-SARS-CoV-2 drugs [18], is the prime concern, hence contradictions on lopinavir/ritonavir, remdesivir treatment have been reported in recent literature. Favipiravir demonstrated good recovery in some of the cases of COVID-19. Umifenovir/Arbidol is also shown reduced mortality in few studies [19].

In this scenario, using the structure-based drug design approach for the specific protein target-based ligands with low energy conformation can be a helpful tool for the clinicians to choose the right therapeutic molecule for further analysis [20]. In the current research paper, molecular docking has been performed along with the analysis of absorption, distribution, metabolism, excretion, and toxicity predictions for each of the testing anti-viral molecule along with the binding free energy potential to predict the potent binding potential of compounds against virus targets.

\section{Methods}

\subsection{Data Collection:}

A library of 52 anti-viral drugs was made by downloading drug structures from Pubchem based on available literature. These drugs were tested for the possible anti-viral efficacy in response to selected targets SARS-CoV-2 proteins using in-silico docking using Maestro 12.4 version of Schrodinger Suite-2020-1. A molecular Docking study was performed to see the possible efficacy of these compounds for the selected five targets. The crystal structure of 5 potential target SARS-CoV-2 proteins: RdRp (PDB ID-6M71), spike receptor-binding domain (PDB ID-6M0J), main protease (PDB ID-6LU7), ACE 2 (PDB ID-1R4L), NSP15 Endoribonuclease (PDB ID-6W01) was downloaded from RCSB Protein data bank (RCSB-PDB).

\subsection{Protein and Ligand Preparation:}

The crystal structure of 5 potential target proteins RdRp (PDB ID-6M71), spike receptor-binding domain (PDB ID-6M0J), main protease (PDB ID-6LU7), ACE2 (PDB ID-1R4L), NSP15 Endoribonuclease (PDB ID-6W01) were prepared using the protein preparation wizard of Maestro. In brief, it adds hydrogen atoms, missing residues, and refined loops along with fixation of side chains and the addition of disulfide bonds. Further, the protonation states of amino acids at $\mathrm{pH}$ 7.4 were generated by the PROPKA module which mimics physiological conditions $[21,22]$. Besides this, the protein structures were minimized using the OPLS-3e force field of the Schrodinger suite. The key active site residues were used to generate a grid box for each protein target as mentioned in the literature $[23,24]$.

The 52 anti-viral drugs 3D structure in SDF format were downloaded from PubChem and prepared using the Ligprep module of Schrodinger suite [25]. This module automatically generates enantiomers and tautomers, which increases the total number of anti-viral drugs from 52 to 88 . It added protonation states at $\mathrm{pH}$ 7.4, using Epik. [26]. To check the potential binding efficacy of these drugs Glide SP module was used for in-silico docking. This was followed by docking of top 20 drug molecule in Glide XP (extra precision) mode, which provides accurate binding efficacy [27]. Further, the 3D structure of proteins and 2D structures of drugs and their $2 \mathrm{D}$ interactions were prepared using the respective module of Schrodinger.

\subsection{Binding Free Energy (MM-GBSA) Calculation:}

Binding free energy (MMGBSA) of selected anti-viral drugs with respective protein targets was calculated using OPLS 3e force field in solvation condition of Prime module of Schrodinger suite. Prime modules provide $\Delta \mathrm{G}$ bind between protein and ligand complexes [28]. The tope 5 complexes after docking was subjected to $\Delta \mathrm{G}$ calculations which arementioned in Table 1 .

\subsection{ADME Properties}

The ADME properties of selected lead molecules were calculated using the ADME and molecular properties module of the Schrodinger suite. The physicochemical properties include molecular weight (MW), surface accessibility (SASA), hydrogen bond acceptor (HBA), hydrogen bond donor (HBD), octanol-water coefficient (Po/w, QPlog S), polar surface area (PSA), number of nitrogen and oxygen atoms, rule of 5 , rings atoms and rule of 3 were calculated and listed in Table 2.

\section{Results}

The use of the previously known anti-viral drugs and their derivatives is promising until a permanent treatment is available. In this study, docking studies were performed over the five potential target sites or binding pockets of SARS-CoV-2 to find the potential binding molecule to combat the life-threatening coronavirus disease. Table 1 summarizes the top five lead molecules which bind with strong affinity with their respective target proteins. Among the 52 screened drugs against the SARS-CoV-2 almost 16 molecules have been shown inhibiting potential. The molecular docking with 5 potential target proteins of SARS-CoV-2 revealed the anti-viral potential of these 16 lead molecules against COVID-19 infection with some common target interactions (Table1). 
Table 1

List of potential lead molecules against SARS-CoV-2 proteins [Binding energy MMGBSA] and Binding affinity (XP G Score) of selected anti-viral

\begin{tabular}{|c|c|c|c|c|}
\hline Protein PDB ID & Ligand ID & Name & XP G Score & MMGBSA \\
\hline \multirow[t]{5}{*}{ 6M71 (SARS-CoV-2 RNA-dependent RNA polymerase) } & 60855 & Zanamivir & -9.572 & -46.38 \\
\hline & 154234 & Peramivir & -8.855 & -4.37 \\
\hline & 5280544 & Herbacetin & -7.85 & -50.43 \\
\hline & 5362119 & Lisinopril & -8.561 & -35.48 \\
\hline & 54892 & Quinapril & -8.102 & -14.16 \\
\hline \multirow[t]{5}{*}{ 6M0J-RBD (Spike receptor-binding domain) } & 5280544 & Herbacetin & -4.836 & -46.24 \\
\hline & 60855 & Zanamivir & -4.582 & -32.88 \\
\hline & 168849 & Pectolinarin & -4.459 & -39.42 \\
\hline & 37542 & Ribavirin & -4.275 & -43.06 \\
\hline & 10445549 & Galidesivir BCX4430 & -4.106 & -23.66 \\
\hline \multirow[t]{5}{*}{ 6LU7 (SARS-CoV-2 main protease) } & 5280544 & Herbacetin & -8.691 & -54.54 \\
\hline & 121304016 & Remdesivir & -8.377 & -110.02 \\
\hline & 5282150 & Rhoifolin & -7.627 & -71.41 \\
\hline & 168849 & Pectolinarin & -6.889 & -67.8 \\
\hline & 45375808 & Sofosbuvir & -6.808 & -82.04 \\
\hline \multirow[t]{5}{*}{ 1R4L (Inhibitor Bound Human ACE-Related Carboxypeptidase (ACE2)) } & 60172 & Adefovir & -10.296 & -58.26 \\
\hline & 5291 & Imatinib & -9.046 & -108.81 \\
\hline & 56640146 & Dasabuvir & -8.294 & -79.08 \\
\hline & 60855 & Zanamivir & -8.196 & -35.08 \\
\hline & 5282150 & Rhoifolin & -7.989 & -63.46 \\
\hline \multirow[t]{6}{*}{ 6W01 (NSP15 Endoribonuclease from SARS-CoV-2) } & 37542 & Ribavirin & -8.081 & -26.36 \\
\hline & 60855 & Zanamivir & -6.502 & -32.95 \\
\hline & 188323 & Cirsimaritin & -5.425 & -38.62 \\
\hline & 87718162 & 2H-Cyclohepta[b] & -4.905 & -35.2 \\
\hline & & thiophene-3-carboxamide & & \\
\hline & 121304016 & Remdesivir & -4.798 & -66.74 \\
\hline
\end{tabular}


Table 2

ADME properties for the lead molecules

\begin{tabular}{|c|c|c|c|c|c|c|c|c|c|c|c|c|c|}
\hline $\begin{array}{l}\text { PDB } \\
\text { ID }\end{array}$ & Ligand no. & Chemical Name & Mol wt. & SASA & $\begin{array}{l}\text { HB } \\
\text { donor }\end{array}$ & $\begin{array}{l}\text { HB } \\
\text { acceptor }\end{array}$ & $\begin{array}{l}\text { QPlog } \\
\text { Po/w }\end{array}$ & $\begin{array}{l}\text { QPlog } \\
\text { S }\end{array}$ & PSA & $\begin{array}{l}\mathbf{N} \\
\& \\
0\end{array}$ & $\begin{array}{l}\text { Rule } \\
\text { of } 5\end{array}$ & $\begin{array}{l}\text { Ring } \\
\text { atoms }\end{array}$ & $\begin{array}{l}\text { Rule } \\
\text { of } 3\end{array}$ \\
\hline \multirow[t]{5}{*}{$6 \mathrm{M} 71$} & 60855 & Zanamivir & 332.313 & 584.151 & 9 & 12.35 & -2.766 & -0.985 & 223.322 & 11 & 2 & 6 & 1 \\
\hline & 154234 & Peramivir & 328.411 & 570.353 & 6 & 7.2 & 0.542 & -1.892 & 161.383 & 8 & 1 & 5 & 1 \\
\hline & 5280544 & Herbacetin & 302.24 & 518.017 & 4 & 5.25 & 0.429 & -2.89 & 142.141 & 7 & 0 & 16 & 1 \\
\hline & 5362119 & Lisinopril & 405.493 & 723.035 & 5 & 9.5 & -1.204 & -1.371 & 149.231 & 8 & 0 & 11 & 2 \\
\hline & 54892 & Quinapril & 438.522 & 711.294 & 2 & 8.5 & 1.225 & -3.618 & 110.196 & 7 & 0 & 16 & 1 \\
\hline \multirow{5}{*}{$\begin{array}{l}\text { 6MOJ- } \\
\text { RBD }\end{array}$} & 5280544 & Herbacetin & 302.24 & 518.017 & 4 & 5.25 & 0.429 & -2.89 & 142.141 & 7 & 0 & 16 & 1 \\
\hline & 60855 & Zanamivir & 332.313 & 584.151 & 9 & 12.35 & -2.766 & -0.985 & 223.322 & 11 & 2 & 6 & 1 \\
\hline & 168849 & Pectolinarin & 622.579 & 839.584 & 6 & 19.8 & -0.73 & -2.846 & 226.481 & 15 & 3 & 28 & 2 \\
\hline & 37542 & Ribavirin & 244.207 & 426.928 & 5 & 12.3 & -2.564 & -1.485 & 156.493 & 9 & 0 & 10 & 1 \\
\hline & 10445549 & Galidesivir BCX4430 & 265.271 & 480.902 & 7 & 9.1 & -2.151 & -0.725 & 146.442 & 8 & 1 & 14 & 1 \\
\hline \multirow[t]{5}{*}{ 6LU7 } & 5280544 & Herbacetin & 302.24 & 518.017 & 4 & 5.25 & 0.429 & -2.89 & 142.141 & 7 & 0 & 16 & 1 \\
\hline & 121304016 & Remdesivir & 602.583 & 836.121 & 5 & 16.65 & 0.943 & -4.184 & 200.319 & 14 & 2 & 20 & 1 \\
\hline & 5282150 & Rhoifolin & 578.526 & 858.839 & 7 & 19.05 & -1.506 & -3.456 & 233.943 & 14 & 3 & 28 & 2 \\
\hline & 168849 & Pectolinarin & 622.579 & 839.584 & 6 & 19.8 & -0.73 & -2.846 & 226.481 & 15 & 3 & 28 & 2 \\
\hline & 45375808 & Sofosbuvir & 529.458 & 748.602 & 3 & 14.9 & 1.249 & -3.347 & 173.576 & 12 & 2 & 17 & 0 \\
\hline \multirow[t]{5}{*}{ 1R4L } & 60172 & Adefovir & 273.188 & 465.498 & 4 & 10.7 & -0.415 & -1.135 & 137.267 & 9 & 0 & 9 & 1 \\
\hline & 5291 & Imatinib & 493.61 & 890.127 & 2 & 10.5 & 3.581 & -4.873 & 89.54 & 8 & 0 & 30 & 1 \\
\hline & 56640146 & dasabuvir & 493.576 & 797.927 & 2 & 8.75 & 3.555 & -6.692 & 129.501 & 8 & 0 & 22 & 1 \\
\hline & 60855 & Zanamivir & 332.313 & 584.151 & 9 & 12.35 & -2.766 & -0.985 & 223.322 & 11 & 2 & 6 & 1 \\
\hline & 5282150 & Rhoifolin & 578.526 & 858.839 & 7 & 19.05 & -1.506 & -3.456 & 233.943 & 14 & 3 & 28 & 2 \\
\hline \multirow[t]{5}{*}{ 6W01 } & 37542 & Ribavirin & 244.207 & 426.928 & 5 & 12.3 & -2.564 & -1.485 & 156.493 & 9 & 0 & 10 & 1 \\
\hline & 60855 & Zanamivir & 332.313 & 584.151 & 9 & 12.35 & -2.766 & -0.985 & 223.322 & 11 & 2 & 6 & 1 \\
\hline & 188323 & Cirsimaritin & 314.294 & 550.603 & 1 & 4.5 & 2.664 & -4.018 & 91.451 & 6 & 0 & 16 & 0 \\
\hline & 87718162 & $\begin{array}{l}2 \mathrm{H}- \\
\text { Cyclohepta[b]thiophene- } \\
\text { 3-carboxamide }\end{array}$ & 191.247 & 385.9 & 2 & 3 & 1.381 & -2.292 & 50.593 & 2 & 0 & 10 & 0 \\
\hline & 121304016 & Remdesivir & 602.583 & 836.121 & 5 & 16.65 & 0.943 & -4.184 & 200.319 & 14 & 2 & 20 & 1 \\
\hline
\end{tabular}


Table 3

The details of possible proposed lead molecules as a potential anti-SARS-CoV-2 drug

\begin{tabular}{|c|c|c|c|c|}
\hline No & Name & Active against & Mechanism & References \\
\hline 1. & Zanamivir & Influenza viruses & Neuraminidase inhibitor & [29] \\
\hline 2. & Peramivir & Influenza virus & Neuraminidase inhibitor & [30] \\
\hline 3. & Herbacetin & SARS CoV & Inhibitor & [31] \\
\hline 4. & Lisinopril & Acute myocardial infarction, hypertension & ACE inhibitor & [32] \\
\hline 5. & Quinapril & Influenza & ACE inhibitor, RNA polymerase & [33] \\
\hline 6. & Pectolinarin & HSV-1, VACV-WR and DENV-2 & Tyrosinase inhibitor & [34] \\
\hline 7. & Ribavirin & Hepatitis C & Synthetic guanosine analog & [35] \\
\hline 8. & Galidesivir BCX4430 & Hepatitis C & Adenosine analog & [36] \\
\hline 9. & Remdesivir & Ebola virus, Respiratory syncytial virus & Viral RNA polymerase & [36] \\
\hline 10. & Rhoifolin & & & [37] \\
\hline 11. & Sofosbuvir & $\begin{array}{l}\text { Yellow fever, Zika virus, Dengue, Hepatitis C, } \\
\text { Chikungunya viruses }\end{array}$ & $\begin{array}{l}\text { Inhibitor of viral RNA synthesis by inhibiting } \\
\text { NS5B protein }\end{array}$ & [34] \\
\hline 12. & Adefovir & HIV & Reverse transcriptase inhibitor & [38] \\
\hline 13. & Imatinib & SARS CoV and MERS CoV & Tyrosine kinase inhibitor & [39] \\
\hline 14. & Dasabuvir & Hepatitis C virus & $\begin{array}{l}\text { Non-nucleoside inhibitor, Inhibits the action of } \\
\text { NS5B polymerase }\end{array}$ & [38] \\
\hline 15. & Cirsimaritin & Influenza virus & $\begin{array}{l}\text { Downregulating the NF-kb signal transduction } \\
\text { pathway }\end{array}$ & {$[40]$} \\
\hline 16. & $\begin{array}{l}2 \mathrm{H} \text {-Cyclohepta[b]thiophene-3- } \\
\text { carboxamide }\end{array}$ & HIV-1 & Ribonuclease inhibitors & {$[41]$} \\
\hline
\end{tabular}

In light of present findings Zanamivir, Peramivir, Herbacetin, Lisinopril, Quinapril are the top five molecules that showed the potential to bind with SARS-CoV-2 RNA-dependent RNA polymerase (6M71). Similarly, Herbacetin, Zanamivir. Pectolinarin, Ribavirin, Galidesivir BCX4430 are the top five molecules that exhibited the high binding potential to bind with SARS-CoV-2 spike receptor-binding domain protein (6MOJ-RBD). Further, Herbacetin, Remdesivir, Rhoifolin, Pectolinarin, Sofosbuvir are the top potential drugs that bind with SARS-CoV-2 main protease (6LU7). Apart from this, Adefovir, Imatinib, Dasabuvir, Zanamivir, Rhoifolin are the drugs, which showed the possible strong interaction on the 1R4L site. However, Ribavirin, Zanamivir, Cirsimaritin, 2H-Cyclohepta[b]thiophene-3carboxamide, Remdesivir display the possible affinity to bind with NSP15 Endoribonuclease of SARS-CoV-2 (Table 1).

Among the tested drugs in this in-silico study, the present finding suggests the highest binding potential of Remedesivir, Imatinib, Herbacetin, Zanamivir, Ribavirin, Dasabuvir, Rhoifolin, Sofosbuvir, Cirsimaritin, and 2H-Cyclohepta[b]thiophene-3-carboxamide for their respective protein targets. The results showed efficient binding of the potential targets of SARS-CoV-2 with these lead molecules as the best active binders. These interactions suggest their probable mechanism for anti-viral effects against SARS-CoV-2. Our results predict a strong therapeutic potential of these proposed drugs against SARS-CoV-2 infection.

Herbacetine and Rhoifoloin are polyphenolic drugs. polyphenolic drugs are natural antioxidant boosters that contribute to anti-viral therapies since ancient times [42]. Herbal formulations used for alternative therapies have remains a popular choice among clinicians due to their least toxic nature. The potential of Plant Bioactive Compounds was also tested for anti-SARS-CoV-2 potency $[43,44]$. Polyphenols have a high affinity to proteins via hydrogen bonding formation that helps them to inhibit the viral proteases involved in viral replication. Molecular docking studies prove the inhibitory action of polyphenolic compounds against SARS-CoV-2 main protease (Mpro) and spike (S) glycoprotein inhibitors $[45,46]$.

The docking of the proposed ligand molecules with the active site of a receptor determines the orientation of binding capacity, formation of bridges, and possible hydrophilic, hydrophobic interactions along with the amount of energy liberated that refers to the stability of the ligand-receptor complex [47, 48]. In search of the potential lead inhibitor molecules, we have tested various anti-viral candidates for repositioning as SARS-CoV-2 inhibitors. Figure 1 depicts the best docking poses of Proteins with the top docked ligand showing the highest docking score. For instance, $6 \mathrm{M} 71$ have shown the highest docking score with Zanamivir (Figure 1a), 6M0J-RBD, and 6LU7 with Herbacetin (Figure 1b\&C), 1R4L with Adefovir (Figure 1d), and 6W01 with Ribavirin (Figure 1e). Various interactions between the protein with respective docked ligands such as hydrogen bonds, pi-pi interaction have been displayed in Figure $1 \mathrm{a}$-e respectively. Figure 2 represents the structures of Zanamivir (Figure 2a), Herbacetin (Figure 2b), 1R4L with Adefovir (Figure 2c), and Ribavirin (Figure 2d).

There are five prime virus targets $6 \mathrm{M} 71,6 \mathrm{M} 0 \mathrm{~J}-\mathrm{RBD}, 6 \mathrm{LU7}, 1 \mathrm{R} 4 \mathrm{~L}, 6 \mathrm{~W} 01, \mathrm{NSP} 15$ which play a vital role in the mediation of virulence and pathogenicity. Present results revealed that each target is competitively encountered by a potential lead molecule that possibly inhibits the function of the enzyme and reduces the viral load.

RdRp is the most promising therapeutic drug target as it plays a vital role in viral RNA genome replication. The docking study has shown Zanamivir (332.313 $\mathrm{MW}$ ) binds with great affinity with the RdRp. In the binding pocket of the enzyme Zanamivir forms various interactions including 7 hydrogen bonds at polar 
and positive charged residues. The amino acids Arg 553, Arg 555, Thr 556, Asp 623, Asp 760 involved in the formation of hydrogen bonds with Zanamivir (Figure 1a). The highest docking score and binding free energy exhibited by Zanamivir against 6M71 active site residue suggest its potential anti-viral efficacy.

Spike receptor-binding domain is an essential requirement for mediation of SARS-CoV-2 into the host cell [49]. The attachment and entry of virus within the host cell are mediated by spike protein which makes it a suitable target for drugs that can bind and prevent the entry of virus within the host cell. The docking study revealed Herbacetin (302.24 MW) showed a higher potential of binding at the active site of 6MOJ-RBD, as this ligand interacts with high affinity within the active site pocket. Here, various interactions of Herbactin with active site amino acid residue of 6M0J-RBD includes the formation of 3 pi cation by Lys 458, Arg 457, Arg454 along and 4 hydrogen bonds with Ser460, Lys 458, and Ser 469 amino acids at positively charged polar regions (Figure 1b).

SARS-CoV-2 encodes two distinct proteases, named papain-like cysteine protease (PLpro) and chymotrypsin-like cysteine protease known as (3C-like protease/ 3CLpro/ Main protease /Mpro). The SARS CoV Mpro is an essential requirement for processing of the polyproteins that are translated from the viral RNA [50]. SARS-CoV-2 Mpro inhibitors are the prime molecules with possible anti-viral efficacy. Therefore, Mpro inhibitory drugs with less toxicity to humans proteases have been considered for virus restriction because no human proteases with a similar cleavage specificity are known [51]. Present molecular docking study showed Herbacetin (302.24 MW) binds in the 6LU7 catalytic site of SARS-CoV-2 were negatively charged and polar residues TYR54, GLU 166, THR 190 in the pocket involved in the formation of 3 hydrogen bonds and HIS 41residue form pi interaction with the drug respectively (Figure 1c). These amino acid residues play an essential role in the catalytic activity of Mpro [50].

ACE2 the negative regulator of the renin-angiotensin system, which is an essential mediator of SARS-CoV-2 infection is widely expressed in the lungs, cardiovascular system, gut, kidneys, central nervous system, and adipose tissue of humans [52, 53]. The interactions between the receptor-binding domain of viral spike (S) protein with surface-expressed human ACE2 is an essential requirement for virus pathophysiological modulations. The present study reveals that Adefovir (273.188 MW) acts as a potential candidate for the inhibition of the 1R4L receptor site. At the active site, the involvement of the amino acid residues HIS 345, PRO 346, HIS 505, ARG 273, ALA 348, ARG 514 which forms 7 hydrogen bonds with Adefovir along with a potential salt bridge with Zn 803 validates its anti-viral efficacy (Figure 1d). Various potential drugs that were proposed as an anti-viral agent (including hydroxychloroquine and chloroquine) against SARS-CoV-2 have the potential ACE2 inhibitory activity [54].

The docking study with NSP15 Endoribonuclease of SARS-CoV-2 reveals the potential biding of the target with the anti-viral drug Ribavirin. Ribavirin (244.207 MW), also known as Tribavirin is an antiviral drug with a possible efficacy against HCV and Flavivirus infection [55].. Ribavirin showed the highest binding affinity for the active site residue of the endoribonuclease. Here, active site residues LYS 290, VAL 292, SER 294, LEU 346 forms 6 hydrogen bonds with ribavirin (Figure 1e).

The physicochemical properties such as molecular weight (MW), surface accessibility (SASA), hydrogen bond acceptor (HBA), hydrogen bond donor (HBD), octanol-water coefficient (Po/w, QPlog S), polar surface area (PSA), number of nitrogen and oxygen atoms, rule of 5, rings atoms and rule of 3 of selected lead molecules were calculated and listed in Table 2. The ADME properties of lead molecules showed their potency as an efficient anti-viral drug against COVID-19.

\section{Discussion}

Apart from all the advancements in drug therapeutics only patient management is being possible in the case of COVID-19 disease. There is no treatment available to immediately stop virus replication or virulence [2]. In this scenario where the virus is possibly shifted from an interspecies intermittent host and has a potential similarity with the earlier existing virus attacks, broad-spectrum anti-viral drugs and inhibitors are the best suitable option to manage health care challenges. Even though various clinical and sub-clinical studies are ongoing to manage SARS-CoV-2 pandemic still the promising role of in silico methods, molecular docking, and binding studies for prediction of new potential drugs for repurposing can't be ignored [56-58].

Certification and approval of new lead molecules for any specific disease by the Food and Drugs Administration (FDA) is time-consuming and difficult. The time taken for the experiments and validation is also a big deal in the case of novel therapeutics determination. In the emergency of COVID-19, the drug repurposing is not only a convenient way but an economically beneficial idea too [37, 59]. The benefits of FDA-approved drugs with potential inhibition capacity of SARS-CoV-2 can be of great significance in this regard. Sofosbuvir, and Ribavirin. are the drugs, which are active against Hepatitis $\mathrm{C}$ Virus (HCV) [60]. Besides, clinical trials are continuously being made to develop anti-RdRp compounds against different viruses. The half-maximal Effective Concentration (EC50) for Ribavirin against COVID-19 is $109.5 \mu \mathrm{M}$, which makes it a potential candidate but the trouble is to make it available for the massive global population without any financial or racist restriction [61, 62]. These issues made similar drugs a potential alternative in these cases (Table 3 ). The conserved active site of the RdRp has two aspartate residues protruded to enhance surface accessibility through the nucleotide channel (free nucleotides can pass through). It served as a potential target for various lead molecules with RNA viruses replication inhibitor including Hepatitis C Virus (HCV), Zika Virus (ZIKV), and Coronavirus (CoV) [63-65].

Viral RNA polymerase inhibitor drugs such as Ribavirin, Galidesivir BCX4430 and other viral replication inhibitor drugs such as tyrosine kinase modulators such as Imatinib and pectolinarin, non-nucleoside inhibitor such as Dasabuvir are some lead molecules with the possible anti-viral efficacy against SARS-CoV2. Apart from these signal transduction pathway down-regulators such as Cirsimaritin, Ribonuclease inhibitors such as $2 \mathrm{H}-\mathrm{Cyclohepta[b]thiophene-3-}$ carboxamide are some potential drugs that could limit the severity of the SARS-CoV-2 infection [66]. The results suggest the potential of these drugs for drug repurposing against SARS-CoV-2. Even though with each passing day new research findings create better possibilities with the discovery of new molecules but the consistent monitoring approach for drug repurposing can't be ignored. The continuous prediction for the potential drugs is an essential requirement until the world overcomes the pandemic completely.

The vital viral proteins, which are essential for viral replication and viral entry and viral binding in the host cell are targeted in the present study to check the efficacy of anti-viral drugs. The most effective and potential target site for SARS-CoV-2 is ACE2. The inhibition or blockage of this active site could be of great 
significance to predict the potential mediation of infection [67]. Drugs such as Lisinopril and Quinapril have shown ACE2 blocking activity could be a potential lead molecule for the SARS-CoV-2 infection. The virus entry in a cell is highly dependent on proteases. SARS-CoV-2 has two distinct types of proteases, responsible for active existence named as main proteases and papain proteases. This helps the non-structural Nsp10/16 complex protein target mediates the viral translation. The protease blocker lead molecules are most probably the ones that restrict the infection indirectly [68]. Various studies showing the antiviral efficacy of anti-viral drugs against the prime target of SARS-CoV-2, which have been summarized in Table 3 are in concordance with our study and further confirms our finding.

\section{Conclusions}

The present work focused on computational approach for repurposing against SARS-CoV-2. There are lots of reports on computational approaches for drug repurposing against SARS-CoV-2, however, there are scarce reports on combinatorial approaches where multiple targets are being analysed. The novelty of present work is that herein we have selected five most potential target of SARS-CoV-2 (Spike, RdRp, ACE-II, RBD, endonuclease) for searching better drug which can be repurposed for the treatment of COVID-19. Herbacetin andZanamivir is the top two potential lead molecules for RdRp. Herbacetin, Ribavirin are the top two potential lead molecules for the RBD of the spike protein. Further Rhoifolin, Sofosbuvir are two top lead molecules those bind with Mpro. Apart from this, the highest binding affinity molecule Imatinib; Dasabuvir, Rhoifolin have shown the maximum binding potential for the site ACE2. Remedesivir is showed the highest binding affinity with endoribonuclease. However, after Remedesivir, Cirsimaritin and 2H-Cyclohepta[b]thiophene-3-carboxamide lead molecule have shown the pretty good binding potential to endoribonuclease.

In combination with the prediction of these lead molecules, to decipher the actual in vivo potential of these drugs against SARS-CoV-2 clinical studies must be warranted. In conclusion, the present In silico molecular docking study predicts that Remedesivir, Imatinib, Herbacetin, Zanamivir, Ribavirin, Dasabuvir, Rhoifolin, Sofosbuvir, Cirsimaritin, and 2H-Cyclohepta[b]thiophene-3-carboxamide are the potential drugs that could be a ray of hope for drug repurposing against SARS-CoV-2 with a special emphasis on the anti-viral potential of Zanamivir for RdRp enzyme inhibition, Herbacetin against RBD and Mpro, Adefovir for ACE2 enzyme and Ribavirin for endoribonuclease. Further our results showed that Herbactin is the drug which can simultaneously inhibit two most potent target of SARS-CoV-2 spike protein and Mpro and therefore can be potentially used to cure infection in most efficacious way.

Considering the high virulence and contagious nature of SARS-CoV-2, it is a dire need to check more than enough therapeutic targets and develop few drugs which could not only be effective against the ongoing pandemic but will be used further in case of any similar future virus attack with a little modified version of SARS-CoV-2.

\section{Abbreviations}

SARS-CoV-2: severe acute respiratory syndrome coronavirus -2, MERS-CoV: Middle East Respiratory Syndrome, 6M71: RNA-dependent RNA polymerase, 6M0JRBD: Spike receptor-binding domain protein, 6LU7: Main proteases, 1R4L: Inhibitor Bound Human ACE-Related Carboxypeptidase, 6W01: NSP15

Endoribonuclease, NSP: Nonstructural protein, ACE2: Angiotensin-converting enzyme2, RdRp: RNA-dependent RNA polymerase, ACE: Angiotensin-converting enzyme, PDB: Protein data bank, MW: molecular weight, SASA: surface accessibility, HBA: hydrogen bond acceptor, HBD: hydrogen bond donor, PSA: Polar surface area,

\section{Declarations}

We hereby declare that the content of the manuscript has not been published, or submitted for publication elsewhere. All authors read and approved the manuscript for publication.

\section{Ethics Approval and Consent to Participate}

The article does not contain any studies on humans/animals.

\section{Consent For Publication}

Not applicable.

\section{Availability of Data and Materials}

All data generated or analyzed during this study are included in this published article.

\section{Competing Interest}

Authors have no competing interest

\section{Funding}

None.

\section{Authors' Contribution}

AP conceptualized, designed, perform docking studies, wrote and proofread the manuscript. TZ and RK interpreted data, wrote the manuscript and proofread the manuscript. DSP prepared the molecule library design and contributed to software operation. RD and YM helped in molecule library preparation and data 
collection. All the authors approved the final manuscript to be published.

\section{Acknowledgements}

The authors would like to thank team Schrodinger for providing the software.

\section{References}

1. Bogoch II, Watts A, Thomas-Bachli A, Huber C, Kraemer MU, Khan K (2020) Periodicity in epidemiological models, pneumonia of unknown etiology in Wuhan, China: potential for international spread via commercial air travel. Journal of Travel, Medicine. 2020

2. Liu C, Zhou Q, Li Y, Garner LV, Watkins SP, Carter LJ, Smoot J, Gregg AC, Daniels AD, Jervey S, Albaiu D (2020) Research and development on therapeutic agents and vaccines for COVID-19 and related human coronavirus diseases. 2020

3. Shah B, Modi P, Sagar SR (2020) In silico studies on therapeutic agents for COVID-19: Drug repurposing approach. Life Sciences. 2020 Jul 1;252:117652

4. Baig AM, Khaleeq A, Ali U, Syeda H (2020) Evidence of the COVID-19 virus targeting the CNS: tissue distribution, host-virus interaction, and proposed neurotropic mechanisms. ACS chemical neuroscience. 2020 Mar 13(7):995-998

5. Kupferschmidt K, Cohen J (2020) Will novel virus go pandemic or be contained?

6. Rothan HA, Byrareddy SN The epidemiology and pathogenesis of coronavirus disease (COVID-19) outbreak. Journal of autoimmunity. 2020 May 1;109:102433

7. Elfiky AA (2020) Anti-HCV, nucleotide inhibitors, repurposing against COVID-19. Life sciences. 2020 May 1;248:117477

8. Wrapp D, Wang N, Corbett KS, Goldsmith JA, Hsieh CL, Abiona O, Graham BS, McLellan JS (2020) Cryo-EM structure of the 2019-nCoV spike in the prefusion conformation. Science 2020 Mar 13(6483):1260-1263

9. Kivrak A, Ulaş B, Kivrak H (2021) A comparative analysis for anti-viral drugs: Their efficiency against SARS-CoV-2. International immunopharmacology. 2021 Jan;90:107232

10. Adamson CS, Chibale K, Goss RJ, Jaspars M, Newman DJ, Dorrington RA (2021) Antiviral drug discovery: Preparing for the next pandemic. Chemical Society Reviews. 2021

11. Paul SS, Biswas G (2021) Repurposed Antiviral Drugs for the Treatment of COVID-19: Syntheses, Mechanism of Infection and Clinical Trials. Mini reviews in medicinal chemistry. 2021 Jun 1;21(9):1123-43

12. Aghaee E, Ghodrati M, Ghasemi JB (2019) In silico exploration of novel protease inhibitors against coronavirus 2019 (COVID-19). Informatics in Medicine Unlocked. 2021 Jan 1;23:100516

13. Zhang Y, Tang LV (2020) Overview of Targets and Potential Drugs of SARS-CoV-2 According to the Viral Replication. Journal of proteome research. 2020 Dec 21

14. Costanzo M, De Giglio MA, Roviello GN (2020) SARS-CoV-2: recent reports on antiviral therapies based on lopinavir/ritonavir, darunavir/umifenovir, hydroxychloroquine, remdesivir, favipiravir and other drugs for the treatment of the new coronavirus. Current medicinal chemistry. 2020 Aug 1;27(27):4536-41

15. Jo S, Kim S, Shin DH, Kim MS (2020) Inhibition of SARS-CoV 3CL protease by flavonoids. Journal of enzyme inhibition and medicinal chemistry. 2020 Jan 1;35(1):145-51

16. Wu R, Wang L, Kuo HC, Shannar A, Peter R, Chou PJ, Li S, Hudlikar R, Liu X, Liu Z (2020) An update on current therapeutic drugs treating COVID-19. Curr Pharmacol Rep

17. Wu YS, Lin WH, T-A Hsu J, Hsieh HP (2006) Antiviral drug discovery against SARS-CoV. Current medicinal chemistry. 2006 Jul 1;13(17):2003-20

18. Rosa SG, Santos WC (2020) Clinical trials on drug repositioning for COVID-19 treatment. Revista Panamericana de Salud Pública. 2020 May 8;44:e40

19. Jomah S, Asdaq SM, Al-Yamani MJ (2020) Clinical efficacy of antivirals against novel coronavirus (COVID-19): A review. Journal of infection and public health. 2020 Aug 3

20. Carlesso A, Chintha C, Gorman AM, Samali A, Eriksson LA (2019) Merits and pitfalls of conventional and covalent docking in identifying new hydroxyl aryl aldehyde like compounds as human IRE1 inhibitors. Scientific reports. 2019 Mar 4;9(1):1-0

21. Sastry GM, Adzhigirey M, Day T, Annabhimoju R, Sherman W (2013) Protein and ligand preparation: parameters, protocols, and influence on virtual screening enrichments. Journal of computer-aided molecular design. 2013 Mar;27(3):221-34

22. Bas DC, Rogers DM, Jensen JH (2008) Very fast prediction and rationalization of pKa values for protein-ligand complexes. Proteins: Structure Function and Bioinformatics 2008 Nov 15(3):765-783

23. Elfiky AA, Ismail A (2019) Molecular dynamics and docking reveal the potency of novel GTP derivatives against RNA dependent RNA polymerase of genotype 4a HCV. Life sciences. 2019 Dec 1;238:116958

24. Khan SA, Zia K, Ashraf S, Uddin R, Ul-Haq Z (2020) Identification of chymotrypsin-like protease inhibitors of SARS-CoV-2 via integrated computational approach. Journal of Biomolecular Structure and Dynamics. 2020 Apr 11:1-0

25. Jorgensen WL, Tirado-Rives J (1988) The OPLS [optimized potentials for liquid simulations] potential functions for proteins, energy minimizations for crystals of cyclic peptides and crambin. Journal of the American Chemical Society. 1988 Mar 1;110(6):1657-66

26. Shelley JC, Cholleti A, Frye LL, Greenwood JR, Timlin MR, Uchimaya M (2007) Epik: a software program for pK a prediction and protonation state generation for drug-like molecules. Journal of computer-aided molecular design. 2007 Dec;21(12):681-91 
27. Friesner RA, Banks JL, Murphy RB, Halgren TA, Klicic JJ, Mainz DT, Repasky MP, Knoll EH, Shelley M, Perry JK, Shaw DE (2004) Glide: a new approach for rapid, accurate docking and scoring. 1. Method and assessment of docking accuracy. Journal of medicinal chemistry 2004 Mar 25(7):1739-1749

28. Genheden S, Kuhn O, Mikulskis P, Hoffmann D, Ryde U (2012) The normal-mode entropy in the MM/GBSA method: effect of system truncation, buffer region, and dielectric constant. Journal of chemical information and modeling. 2012 Aug 27;52(8):2079-88

29. Coleman CM, Sisk JM, Mingo RM, Nelson EA, White JM, Frieman MB (2016) Abelson kinase inhibitors are potent inhibitors of severe acute respiratory syndrome coronavirus and Middle East respiratory syndrome coronavirus fusion. Journal of virology. 2016 Sep 12;90(19):8924-33

30. Alame MM, Massaad E, Zaraket H (2016) Peramivir: a novel intravenous neuraminidase inhibitor for treatment of acute influenza infections. Frontiers in microbiology 2016 Mar 31:7:450

31. Jo S, Kim S, Shin DH, Kim MS (2020) Inhibition of SARS-CoV 3CL protease by flavonoids. Journal of enzyme inhibition and medicinal chemistry. 2020 Jan 1;35(1):145-51

32. Goa KL, Balfour JA, Zuanetti G (1996) Lisinopril. Drugs. 1996 Oct;52(4):564-88

33. Boltz DA, Aldridge JR, Webster RG, Govorkova EA (2010) Drugs in development for influenza. Drugs. 2010 Jul;70(11):1349-62

34. Simões LR, Maciel GM, Brandão GC, Kroon EG, Castilho RO, Oliveira AB (2011) Antiviral activity of Distictella elongata (Vahl) Urb.(Bignoniaceae), a potentially useful source of anti-dengue drugs from the state of Minas Gerais, Brazil. Letters in applied microbiology. 2011 Dec;53(6):602-7

35. Te HS, Randall G, Jensen DM (2007) Mechanism of action of ribavirin in the treatment of chronic hepatitis C. Gastroenterology \& hepatology. 2007 Mar;3(3):218

36. Taylor R, Kotian P, Warren T, Panchal R, Bavari S, Julander J, Dobo S, Rose A, El-Kattan Y, Taubenheim B, Babu Y (2016) BCX4430-a broad-spectrum antiviral adenosine nucleoside analog under development for the treatment of Ebola virus disease. Journal of Infection and Public Health. 2016 May 1;9(3):220-6

37. Martin KW, Ernst E (2003) Antiviral agents from plants and herbs: a systematic review. Antiviral therapy. 2003 Apr 1;8(2):77-90

38. Shah B, Modi P, Sagar SR (2020) In silico studies on therapeutic agents for COVID-19: Drug repurposing approach. Life Sciences. 2020 Jul 1;252:117652

39. Coleman CM, Sisk JM, Mingo RM, Nelson EA, White JM, Frieman MB (2016) Abelson kinase inhibitors are potent inhibitors of severe acute respiratory syndrome coronavirus and Middle East respiratory syndrome coronavirus fusion. Journal of virology. 2016 Sep 12;90(19):8924-33

40. Yan H, Wang H, Ma L, Ma X, Yin J, Wu S, Huang H, Li Y (2018) Cirsimaritin inhibits influenza A virus replication by downregulating the NF-kB signal transduction pathway. Virology journal. 2018 Dec;15(1):1-9

41. Corona A, Desantis J, Massari S, Distinto S, Masaoka T, Sabatini S, Esposito F, Manfroni G, Maccioni E, Cecchetti V, Pannecouque C (2016) Studies on cycloheptathiophene-3-carboxamide derivatives as allosteric HIV-1 ribonuclease H inhibitors. ChemMedChem. 2016 Aug 19;11(16):1709

42. Lou SN, Lai YC, Hsu YS, Ho CT (2016) Phenolic content, antioxidant activity and effective compounds of kumquat extracted by different solvents. Food chemistry. 2016 Apr 15;197:1-6

43. Paraiso IL, Revel JS, Stevens JF (2020) Potential use of polyphenols in the battle against COVID-19. Current Opinion in Food Science. 2020 Sep 9

44. Solnier J, Fladerer JP (2020) Flavonoids: A complementary approach to conventional therapy of COVID-19?. Phytochemistry Reviews. 2020 Sep 18:1-23

45. Tallei TE, Tumilaar SG, Niode NJ, Kepel BJ, Idroes R, Effendi Y, Sakib SA, Emran TB (2020) Potential of plant bioactive compounds as SARS-CoV-2 main protease (Mpro) and spike (S) glycoprotein inhibitors: a molecular docking study. Scientifica. 2020 Dec 23;2020

46. Chojnacka K, Witek-Krowiak A, Skrzypczak D, Mikula K, Młynarz P (2020) Phytochemicals containing biologically active polyphenols as an effective agent against Covid-19-inducing coronavirus. Journal of Functional Foods. 2020 Jul 30:104146

47. Chikhale RV, Gurav SS, Patil RB, Sinha SK, Prasad SK, Shakya A, Shrivastava SK, Gurav NS, Prasad RS (2020) Sars-cov-2 host entry and replication inhibitors from Indian ginseng: an in-silico approach. Journal of Biomolecular Structure and Dynamics. 2020 Jun 20:1-2

48. Zhou Y, Hou Y, Shen J, Huang Y, Martin W, Cheng F (2020) Network-based drug repurposing for novel coronavirus 2019-nCoV/SARS-CoV-2. Cell discovery. $2020 \operatorname{Mar} 16 ; 6(1): 1-8$

49. Su QD, Yi Y, Zou YN, Jia ZY, Qiu F, Wang F, Yin WJ, Zhou WT, Zhang S, Yu PC, Bi SL (2020) The biological characteristics of SARS-CoV-2 spike protein Pro330-Leu650. Vaccine. 2020 Jul 6;38(32):5071-5

50. Zhang L, Lin D, Sun X, Curth U, Drosten C, Sauerhering L, Becker S, Rox K, Hilgenfeld R (2020) Crystal structure of SARS-CoV-2 main protease provides a basis for design of improved a-ketoamide inhibitors. Science. 2020 Apr 24;368(6489):409-12

51. Sencanski M, Perovic V, Pajovic SB, Adzic M, Paessler S, Glisic S (2020) Drug repurposing for candidate SARS-CoV-2 main protease inhibitors by a novel in silico method. Molecules. 2020 Jan;25(17):3830

52. Gheblawi M, Wang K, Viveiros A, Nguyen Q, Zhong JC, Turner AJ, Raizada MK, Grant MB, Oudit GY (2020) Angiotensin-converting enzyme 2: SARS-CoV-2 receptor and regulator of the renin-angiotensin system: celebrating the 20th anniversary of the discovery of ACE2. Circulation research. 2020 May 8;126(10):1456-74

53. Veeramachaneni GK, Thunuguntla VB, Bobbillapati J, Bondili JS (2020) Structural and simulation analysis of hotspot residues interactions of SARS-CoV 2 with human ACE2 receptor. Journal of Biomolecular Structure and Dynamics. 2020 Jun 3:1-1

54. Neri T, Nieri D, Celi A (2020) P-selectin blockade in COVID-19-related ARDS. American Journal of Physiology-Lung Cellular and Molecular Physiology. 2020 Jun 1;318(6):L1237-8

55. Tan EL, Ooi EE, Lin CY, Tan HC, Ling AE, Lim B, Stanton LW (2004) Inhibition of SARS coronavirus infection in vitro with clinically approved antiviral drugs. Emerging infectious diseases. 2004 Apr;10(4):581

56. Wu YS, Lin WH, T-A Hsu J, Hsieh HP (2006) Antiviral drug discovery against SARS-CoV. Current medicinal chemistry. 2006 Jul 1;13(17):2003-20

Page $10 / 12$ 
57. Smith MD, Smith JC (2020) Repurposing Therapeutics for COVID-19: Supercomputer-Based Docking to theSARS-CoV-2 Viral Spike Protein and Viral Spike Protein-Human ACE2 Interface

58. Chauhan DS, Prasad R, Srivastava R, Jaggi M, Chauhan SC, Yallapu MM (2020) Comprehensive review on current interventions, diagnostics, and nanotechnology perspectives against SARS-CoV-2. Bioconjugate Chemistry. 2020 Jul 17;31(9):2021-45

59. Akram M, Tahir IM, Shah SM, Mahmood Z, Altaf A, Ahmad K, Munir N, Daniyal M, Nasir S, Mehboob H (2018) Antiviral potential of medicinal plants against HIV, HSV, influenza, hepatitis, and coxsackievirus: a systematic review. Phytotherapy Research. 2018 May;32(5):811-22

60. Yang PL, Gao M, Lin K, Liu Q, Villareal VA (2011) Anti-HCV drugs in the pipeline. Current opinion in virology. 2011 Dec 1;1(6):607-16

61. Markland W, McQuaid TJ, Jain J, Kwong AD (2000) Broad-spectrum antiviral activity of the IMP dehydrogenase inhibitor VX-497: a comparison with ribavirin and demonstration of antiviral additivity with alpha interferon. Antimicrobial agents and chemotherapy. 2000 Apr 1;44(4):859-66

62. Wang M, Cao R, Zhang L, Yang X, Liu J, Xu M, Shi Z, Hu Z, Zhong W, Xiao G (2020) Remdesivir and chloroquine effectively inhibit the recently emerged novel coronavirus (2019-nCoV) in vitro. Cell research. 2020 Mar;30(3):269-71

63. Elfiky AA, Ismail AM (2018) Molecular docking revealed the binding of nucleotide/side inhibitors to Zika viral polymerase solved structures. SAR and QSAR in Environmental Research. 2018 May 4;29(5):409-18

64. Elfiky AA (2019) Novel guanosine derivatives as anti-HCV NS5b polymerase: a QSAR and molecular docking study. Medicinal Chemistry. 2019 Mar $1 ; 15(2): 130-7$

65. Ganesan A, Barakat K (2017) Applications of computer-aided approaches in the development of hepatitis C antiviral agents. Expert Opinion on Drug Discovery. 2017 Apr 3;12(4):407-25

66. Yan H, Wang H, Ma L, Ma X, Yin J, Wu S, Huang H, Li Y (2018) Cirsimaritin inhibits influenza A virus replication by downregulating the NF-kB signal transduction pathway. Virology journal. 2018 Dec;15(1):1-9

67. Wan Y, Graham R, Baric R, Li F (2020) An analysis based on decade-long structural studies of SARS 3, JVI Accepted Manuscript Posted Online 29 January 2020. J. Virol. 2020

68. Zhang Y, Tang LV (2020) Overview of Targets and Potential Drugs of SARS-CoV-2 According to the Viral Replication. Journal of proteome research. 2020 Dec 21

\section{Figures}

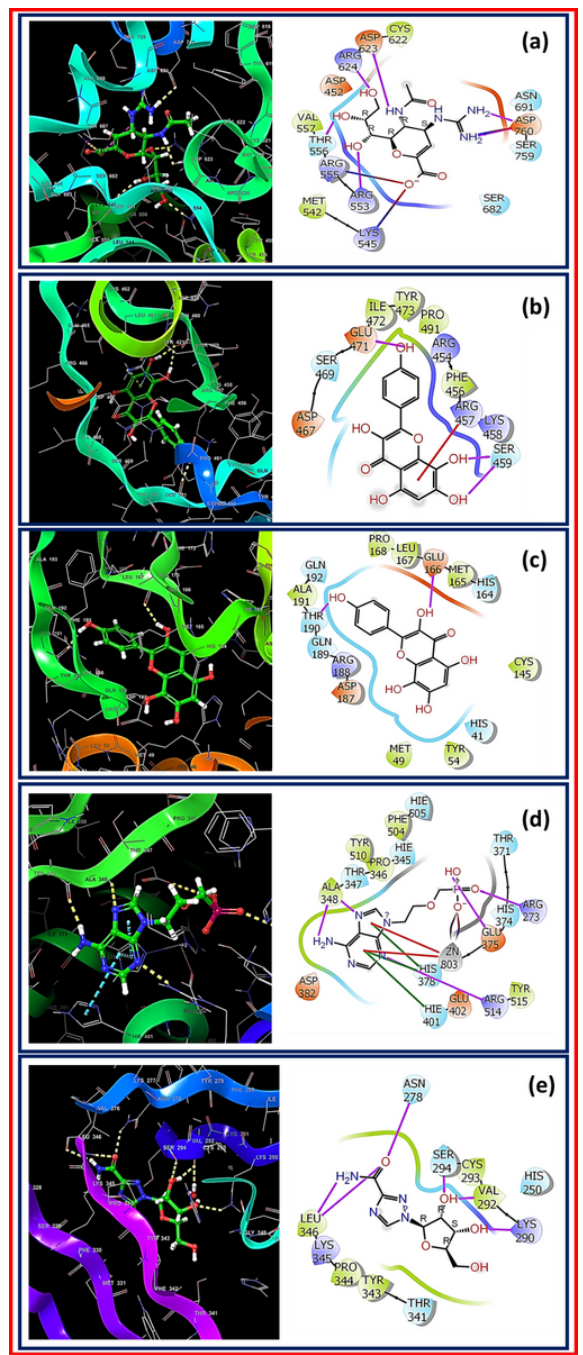


Figure 1

The best docking poses of Proteins with docked ligands. a) 6M71-Zanamivir b) 6M0J-RBD-Herbacetin c) 6LU7- Herbacetin d) 1R4L-Adefovir e) 6W01-Ribavirin along with various interactions between the protein with respective docked ligands (Purple line indicate Hydrogen bond, Green line-Pi-Pi stacking, Red-Pi cation)

Figure 2

represents the structures of Zanamivir (a), Herbacetin (b), Adefovir (c), and Ribavirin (d). 